J ournal of Marketing Management, Volume 24, Issue 1-2, 2008, Pages 185-203

Special Issue: 1 - Creating the Service Experience, 2 - Marketing Myopia

\title{
MYOPIA, CUSTOMER RETURNS AND THE THEORY OF PLANNED BEHAVIOUR
}

\author{
Tamira King ${ }^{1}$, Charles Dennis ${ }^{2}$, and Len Tiu Wright ${ }^{3}$ \\ 1. Corresponding author: \\ Dr Tamira King \\ Brunel University \\ Brunel Business School \\ Room BBS 073 \\ Uxbridge, Middlesex, UB8 3PH, England. \\ Tel: +44 (0) 1895266099 Extension 66099 \\ E-mail Tamira.King@brunel.ac.uk \\ 2.Dr Charles Dennis \\ Brunel University \\ Brunel Business School \\ Room BBS 143 \\ Uxbridge, Middlesex, UB8 3PH, England. \\ Tel: +44 (0) 1895265242 Extension 65242 \\ E-mail: Charles.Dennis@ brunel.ac.uk \\ ${ }^{3}$.Professor Len Tiu Wright \\ Department of Marketing, \\ Leicester Business School, \\ Bede Island, De Montfort University, \\ The Gateway, Leicester, LE1 9BH, UK \\ Tel: +44 (0) 1162506329 \\ e-mail: $\underline{\text { wright@dmu.ac.uk }}$
}




\title{
MYOPIA, CUSTOMER RETURNS AND THE THEORY OF PLANNED BEHAVIOUR
}

\begin{abstract}
As a prevalent and growing form of customer behaviour, deshopping is on the rise. Retailers' focus on good customer service and the offering of lenient returns polices has led to the growth in this fraudulent behaviour of customers in returning goods. This paper considers retailer myopia in the context of dishonest customer returns, applying the Theory of Planned Behaviour (TPB) using a quantitative questionnaire with 535 female consumers. The findings highlight the extent of the behaviour with $50 \%$ admitting to partaking in deshopping. The TPB variables can be utilised to manage and prevent deshopping. The results indicate that currently these customers perceive it to be easy to deshop as there are no consequences with the result that such behaviour continues to grow. If retailers were less myopic they would monitor returns more thoroughly and make it less easy for such customers to get away with undesirable deshopping behaviour. The paper makes recommendations for retailers to manage or alter perceived behavioural characteristics for customers, which in turn, would reduce tendencies for dishonesty in customers returning goods for refunds. Retail myopia is evident with deshopping behaviour with consequences for retailers in time, effort and costs.
\end{abstract}

\section{KEYWORDS}

Fraudulent customer returns, Deshopping; Retailer return policies, Theory of Planned Behaviour, Theory of Reasoned Action

\section{INTRODUCTION}

The marketing myopia pinpointed in this paper concerns the under-representation in the literature and by companies about an aspect of customer behaviour, termed deshopping. This behaviour to do with returning goods to sellers, as presented in this paper on shopping research, leads to increased cost implications for organisations that are detrimental to their good health. This under-representation is in contrast to the emphases in marketing journals, books and conferences that are replete with papers concerning customer retention and loyalty. Both retention and loyalty are key aspects emphasised in marketing strategy development helped along by short term promotional incentives. However, is retention of all customers a desirable outcome for organisations? The answer needs to be balanced between retaining those customers who are of high value with a succession of repeat buying and without difficulties in keeping up repayments against those who present a variety of persistent problems varying from lack of payments to demands for refunds leading to customer disloyalty and malpractices. The paper's research is concerned with the latter regarding customer returns and malpractices because such behaviour is detrimental to the good health of organisations as it consumes their staff's time and energies.

Moreover, it leaves organisations with less than optimum products since these were handled by customers outside their facilities and then returned back to the sellers. The objectives of this paper are twofold. First, to attempt to address the gap in academic literature concerning customer malpractices, in particular, dishonest customer returns. Second, the paper aims to investigate through customer research the extent of customer attitudes and perceptions concerning deshopping with recommendations for retailers in reducing the problem. Three hypotheses, as specified in the section Hypotheses development, were developed for the customer research. 
The authors suggest that the under-representation of this topic in much of the marketing, retailing and practitioner literature points to a neglect of an altogether important marketing function because product returns signify the unsuccessful outcomes of particular buyer-seller relationships. The strategies needed to deal with these are therefore, much less discussed within the literature. Myopia also sets in when organisations wait for the problem of deshopping to go away in the hope that it will correct itself in time or because they do not have coherent strategies in place for their staff to contain, limit or reduce the problem, as the research reported in this paper indicates.

Prior research (Schmidt et al 1999, King et al 2006) indicated that deshopping is a prevalent and growing trend in consumer behaviour and revealed a prevalence of the dishonest consumer behaviour known as deshopping. In effect this means buying something with no intention of keeping it. Deshopping is defined as the:

"deliberate return of goods for reasons other than actual faults in the product, in its pure form premeditated prior to and during the consumption experience."

(Schmidt et al., 1999 p.2)

The returns policies of retailers are facilitating the practices of deshopping and retail borrowing. In today's competitive retail climate, retailers strive to compete in their marketing activities by offering value to customers. The process involves widening customer choice by offering combinations not just of products and prices but also customer service benefits, such as the ability to return unwanted or unsatisfactory merchandise for refund.

In 1960 Levitt's seminal paper pointed out that companies had a focus on products rather than customer needs. We contend that, in the interests of satisfying customers, retailers have (knowingly or otherwise) followed Levitt's principles not just myopically but blindly! As we point out in the paragraph above, retailers encourage customer product returns as part of their competitive marketing policies. This may be short-sighted because it comprises tacit encouragement of customers to deshop. Even more myopic, in our experience, is the unwillingness of those retailers' that we (and, anecdotally, other researchers) have communicated with to tackle deshopping even when the problem and potential solutions are pointed out. Retailers are not just myopic. In our opinion they are deliberately blinkered.

\section{CONSUMPTION, RISK REDUCTION, WARRANTIES AND CUSTOMER SERVICE}

There has been considerable literature on the increasing importance of consumption and its psychological significance. Within the retailing environment researchers (e.g. Donovan et al 1994, Underhill 1999, Wright et al 2006) have shown that a variety of displays and environmental stimuli encourage customers to stay, browse and to buy. Such enhancements and stimuli including colour, lighting and music are found to generally affect customer behavior subliminally through their mood states. As Donovan and Rossiter (1994) found, shoppers experiencing pleasurable shopping environments spend more money within stores with increased desires to communicate with store personnel. As Ward et al (1998) indicated, the products that shoppers consume help create their self images. Customers have different ways of information 
processing and evaluation so their browsing and search functions within retail stores will influence how their information is encoded and stored in memory (Bloch et al 1986, Jarboe et al 1987, Titus et al 1995). Browsing typically involves collecting and taking in perceptual information regarding the sights, smells and sounds in the stores whereas the search function will require garnering information which is productspecific e.g. sizes and price tags or store-specific e.g. locations of amenities and customer service counters for use in product returns. In the course of searching or browsing for products, customers can also be visually attracted to other products. Both functions give ideas and information for future purchases and in the case of deshoppers, the opportunities for further product returns.

In the course of browsing with a view to buying now or later or in the active search for particular products, customers can often come across product alternatives or greater product choices thus evoking their urges to buy immediately. Impulsive purchasing of the additional products can lead to associations of guilt, regret or other negative feelings in the post dissonance stage. Hoch and Loewenstein (1991) observed that unplanned purchases are usually not based on rational and careful thinking. There is little consideration or thought given to consequences about the purchases. This and the emphasis on the importance of self-image products consumed have been shown to have psychological significance (Warde 1994).

Such shopping scenarios can lead to extensive pressure and risks being associated with purchasing decisions and the later consumption of products (Mitchell and McGoldrick 1996). As a result customers see benefit from applying risk reduction in their coping strategies to aid their shopping, such as by going to retailers with the facility for refunding money when goods are taken back.

Return goods policies also allow customers to defer their purchasing decisions until after they gained some experience and enjoyment with the products purchased. It is a simple next step for customers to learn that they can counteract the negativities associated with no-longer-wanted products by returning their purchases. They can reverse their purchase decisions without penalty and thereby, the policy of returns within time limits is open to abuse by deshoppers. The intention of retailers to reduce negative feelings by their customers in order to increase their competitive advantage with their customers (Mitchell and McGoldrick 1996, Schmidt et al 1999) can therefore, backfire and in turn encourage product returns. Such retailer attempts to reduce the risks of purchases for consumers only serve to increase the risks for themselves when it is coupled with loose control of customers returning goods to obtain refunds

Compared to deshopping where returns can be limited to particular stores the problem can be more widespread in other industries. For example, there are cases where customer complaints and deception have led to significant losses for service providers such as those in the financial services, utilities and telecommunications industries (see: Stone et al 2002, Stone 1999). The level of risk for such providers and their costs rise when individual customers create a persistent culture in demanding increased service provisions and interventions including demands for compensation or new substitutes. The mobile phone industry exhibits aspects of these, such as when individual customers are persistent in returning new phones at the brink of taking out new mobile phone contracts or in their insurance claims for new replacement phones. 
Therefore, it is important for retailers to consider how they communicate their offers to customers (Sargeant and West 2001); and with customers (Buttle 2004); and incorporate these two strands into their corporate strategies (Ang and Buttle 2006). A study conducted by Hogarth et al. (2001) addresses satisfaction levels subject to a complaint resolution process. Previous research also indicates that less satisfied people will engage in negative communications (Hanna and Wozniak 2001). Other researchers (e.g. Richins 1983, Kardes and Kim 1991, Stokes and Lomax 2002) have demonstrated that word-of-mouth will influence customers' purchasing decisions. Retailers need to be aware that customers can develop negative associations about 'gimmicks', lack of information or queuing inside their stores. The more satisfied a customer is with how a complaint is handled the less negative comments they are likely to have (Richins 1983, Naylor and Kleiser 2000). Complaints must be properly processed for the retailer not to lose custom and their businesses can benefit by listening to complaints of customers if they are properly processed (Bennett 1997).

Customer retention and loyalty strategies are important considerations as tightening returns policies may affect customer satisfaction levels. This type of customer relationship management is an important part of customer acquisition and retention, which has strong implications for profitability (Ang and Buttle 2006, Goodwin and Ball, 2003). Moreover, research has long ago demonstrated that warranties perform as a persuasive sales variable (Knedall and Russ 1975) and are of relative importance (McClure and Ryans 1968, Roselius 1971, Olsen 1972, Perry and Perry 1976, Darden and Rao 1979).

Retail Crime, on a broader perspective, is a problem threatening the profitability and competitiveness of retailers world-wide (Hollinger et al 1996, Guthrie 1997). Bamfield (2003) demonstrates that retail shrinkage cost retailers the equivalent of 27,258 million Euro in 2002-2003. This demonstrates that a variety of forms of consumer crime are having a significant impact on net profitability of stores, products and retail businesses (Bamfield and Hollinger 2001). Deshopping needs to be seen within this context because of its growing prevalence as a form of return fraud, punishable under The Theft Act (1968) (c.60) if a retailer chose to prosecute a customer for this.

\section{A WIDER PICTURE ON DISHONEST OR FRAUDULENT CUSTOMER RETURNS}

Evidence in previous research (Schmidt et al. 1999) highlighted the prevalence of deshopping. Research with retailers indicates that $82 \%$ of mass market retailers are aware of the deshopping problem. Seventy per cent of independent retailers are aware of customers damaging garments so that they are entitled to a refund and $94 \%$ of independent retailers felt unprotected against this type of shopper (King and Dennis 2006). A case study with a mass market retailer indicates that shrinkage figures due to fraudulent returned garments are contributing to estimated losses in the six figure region. The analysis of clothing returns identified that $50 \%$ of all returns were fraudulent (King et al., 2007).

Fraudulent returns behaviour has previously been investigated via different methods. Cole (1989) investigates seven fraudulent behaviours together in relation to deterrence literature, and found $8 \%$ (of a sample of 157) students engaged in the activity. Wilkes 
(1978) assesses attitudes to the serious fraudulent behaviours of housewives. Ninety nine per cent perceived returning a dress that has been worn as wrong. Jolson (1974) completed observation in department stores and addressed eight consumer offences. Findings indicated that young people were more likely to participate in deshopping behaviour and most admitted repetition of the offence. Zabriskie (1972-1973) completed department store observation and concluded that $12 \%$ of all product returns involved consumers with intent to deceive. Greenberg et al (1979) completed a study of females, finding the profiles of return-prone consumers to be younger, more aggressive, outgoing and importantly they tend to be opinion leaders. Johnson et al. (1985) addressed the frequency of problem behaviours at self-service bulk food bins and recommended consumer education (signs prohibiting munching) to resolve the problem. Gardner et al. (1999) addressed the fraudulent consumer and intentional deceit issues and found results consistent with the Theory of Reasoned Action (TRA). That paper reports little detail or quantification, but nevertheless, that successful use of the TRA has proved to be a useful stimulus for our current paper. Schmidt et al. (1999) addressed the fraudulent consumer and intentional deceit and found that 23\% (of 332 respondents) were self-declared deshoppers. In addition, Schmidt's three focus groups identified deshopping as a process of consumption, risk reduction and exploitation of return policies.

Piron (2000) found that $18 \%$ of a sample of 310 respondents expressed personal involvement in the behaviour. Piron (2000) identified 25 thoughts and emotions, e.g. blaming the store, which could be utilised as predictors of behaviour. In this paper, we integrate Coles (1989) use of deterrence theory and social disapproval, Wilkes' (1978) work on attitudes and Piron's (2000) prediction of behaviour. Inspired by Gardner's and colleagues' (1999) use of the TRA, we use the Theory of Planned Behaviour (TPB) as our integrating framework.

Previous deshopping research has concerned both genders. Nevertheless, Piron \& Young (2000) reported that females 'borrowed' four times as much as men did. Previous research tends to consider many acts of fraudulent behaviour together (Cole 1989, Wilkes 1978, Jolson 1974, Zabriskie 1972-1973, Greenberg et al 1979) and a variety of deshopped products (Ibid; Schmidt et al 1999, Piron \& Young 2000). Nevertheless, Piron \& Young (2000) demonstrate that all but one of sixty items returned after being 'borrowed' (deshopped) were clothing. Hence, this project draws on previous research concentrating on female consumers as the group studied and clothing returns as the product category.

In our view, deshopping is clearly a problem that retailers are myopically failing to address. In this paper, we report on a study on deshopping and womenswear, using a Theory of Planned Behaviour (TPB) framework to draw conclusions and implications that could help provide spectacles for retailers to use in order to see more clearly potential ways of tackling the deshopping problem.

\section{HYPOTHESES DEVELOPMENT}

The Theory of Planned Behaviour (TPB) (Ajzen 1991) attempts to explain variables in human behaviour. The TPB was derived from the Theory of Reasoned Action (TRA) (Ajzen 1985) which holds that a person's volitional (voluntary) behavior is predicted by his or her attitude toward that behavior and how he or she thinks other people would view them if they performed the behavior, the so-called subjective 
norm. A person's attitude towards a behaviour represents evaluation of the behaviour and its outcomes. If a person considers that a behaviour will have a favourable outcome, it is more likely that they will perform that behaviour. Specifically, if a person believes that deshopping will be an easy or pleasant experience, they are more likely to deshop. This leads to our first hypothesis:

\section{H1 Attitude towards deshopping will significantly predict deshopping behaviour}

The subjective norm is seen as a combination of perceived expectations from relevant individuals or groups along with intentions to comply with these expectations. In other words, the person's perception that most people who are important to him or her think he should or should not perform the behavior in question (Ajzen 1985). Specifically, if a person believes that people who are important to them think that they should deshop, then they are more likely to deshop. Thus:

H2 Shoppers' perceptions of the extent to which others who are important to them approve or disapprove of deshopping (subjective norm) will significantly predict deshopping behaviour.

Since attitude and subjective norm cannot be the exclusive determinants of behavior where an individual's control over the behavior is incomplete, The TPB purports to improve on the TRA by adding a new component, "perceived behavioral control." 'Perceived behavioural control' is defined as the ease or difficulty that the person perceives of performing the behaviour. Empirical studies have demonstrated that the addition of perceived behavioural control has significantly improved the modelling of behaviour (Ajzen 1991). Previous research has found the TPB to be particularly useful in programmes aiming to convert undesirable to desirable behaviour, e.g. quitting cigarette smoking (Devries \& Backbier 1994), condom use and safe sex (Boldero et al 1992). Therefore, TPB and particularly perceived behavioural control should be a useful model for studying deshopping analysis, where the aim is to control an undesirable behaviour. This leads to:

H3 Shoppers' perceptions of the ease of carrying out deshopping (perceived behavioural control) will significantly predict deshopping behaviour. 


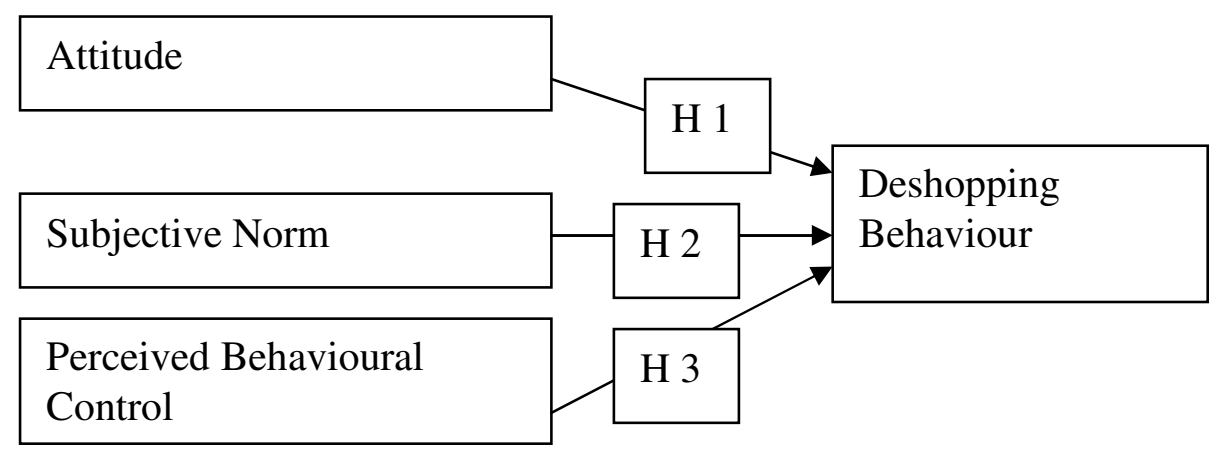

Figure 1. Schematic representation of hypotheses

Ajzen (1991) suggested the inclusion of other variables such as 'intention' or 'past experience'. TPB has often been criticised on the grounds that there is insufficient evidence to justify these extra variables. Therefore, we ignore these in our quantitative approach, preferring the simpler model unless a more complex one is demonstrably better (applying the principle of Occam's razor: see Breakwell et al., 2000.)

\section{METHODOLOGY}

A convenience mall intercept questionnaire survey was utilised to gather quantitative data from 535 female shoppers in two shopping centres. This sampling provides high quality data that can be as accurate as other methods such as random sampling of postal addresses (Bush and Hair, 1985). The technique is more likely to select respondents who stay longer, and thus is more likely to be representative of shoppers' behaviours than would be a true random sample (Nowell and Stanley, 1991).

Questionnaires were completed in two separate shopping locations. Two (out of the 12 contacted) UK shopping centres granted permission for the questionnaire surveys, both in south-east UK. The shopping centres utilised for questionnaire completion were firstly a regional centre in a large town, with well over 100 stores, with a large geographical pull. The second centre was a small sub-regional shopping centre with between 50 and 100 stores and a local catchment.

Researchers intercepted respondents near female fashion stores, for example, Oasis, Warehouse, Morgan, Next and Marks \& Spencer. Interview times were 11am - 8pm Thursday and Friday; 10am - 5.30pm Saturdays; and 10am - 4pm Sundays. The respondents were thus as representative as practicable of the target group.

\section{Questionnaire}

A further criticism of TPB has been that its application has been held back by uncertainties about the design of the questionnaires' (East, 1997, p.133). In this study, therefore, we have followed the standardised TPB questionnaire design procedure recommended by East, using the NEWACT program associated with East's book.

'Attitude' might conceivably consist of any number of components, but we have followed East's approach in using just four in our model:

(i) 'For me, returning clothes is a (unpleasant...pleasant) experience 
(ii) 'For me, returning clothes is a (difficult...easy) experience

(iii) 'For me, returning clothes for dishonest reasons is (unpleasant...pleasant)

(iv) 'For me, buying clothes that I know I am going to return is (Unpleasant...pleasant).

Answers were recorded on seven point scales:

extremely/quite/slightly/neither/slightly/quite/extremely. These were then coded from 1 (unpleasant or difficult end of the scale) to 7 (pleasant or easy end). Cronbach alpha for these four items was 0.67, i.e. above the minimum of 0.6 (Davis and Consenza, 1988). These four items were therefore summed to yield the overall 'Attitude' scale.

Although there are a number of normative beliefs that will affect the subjective norm, and control beliefs affecting perceived behavioural control, East's approach does not use more of these dimensions in a factor analysis. The reason is the need, in the model, to keep the subjective norm and perceived behavioural control variables mutually exclusive. Therefore in our study just two items were selected for each of these variables.

\section{Subjective Norm:}

(v) Most people who are important to me think I should return an outfit after I wore it for a special occasion (unlikely...likely).

(vi) Most people who are important to me think I should damage clothes so I am entitled to a refund (unlikely...likely).

The Pearson R for these two items was 0.55 (for only two items the 'alpha' has no absolute meaning but SPSS nonetheless reports this statistic as 0.71), which indicated that these two items were closely enough related to use as a compound variable. These two items were therefore summed to yield the overall 'Subjective norm' scale.

\section{Perceived Behavioural Control:}

(vii) Returning worn clothes as new is (difficult...easy).

(viii) Returning clothes deliberately damaged is (difficult...easy)

Again, the responses were coded on 1-7 scales. The Pearson $\mathrm{R}$ for these two items was 0.43 ('alpha' $=0.60$ ), which again indicated that these two items were closely enough related to use as a compound variable. These two items were therefore summed to yield the overall Perceived Behavioural Control scale.

Deshopping Behaviour was measured using seven items:

(ix) Returning clothes after wearing them is something I have done (rarely...often)

(x) I have a lot of experience damaging clothes so that they can be returned (unlikely...likely)

(xi) I would return worn clothes as new (unlikely...likely)

(xii) I would return deliberately damaged clothes (unlikely...likely)

(xiii) For me, returning clothes for dishonest reasons is (unlikely...likely)

(xiv) For me, damaging clothes so that I can return them is (unlikely...likely)

(xv) For me, buying clothes that I know $\mathrm{I}$ am going to return is (unlikely...likely).

The deshopping behaviour questions do not have a mid point, as the answer 'neither' could be given by someone who would never deshop. These items have therefore been coded 1-6. The alpha for these seven items was 0.77 . The seven items were therefore summed to yield the overall 'Deshopping' scale. Most respondents -425 or 
$80 \%$ of the total - scored above zero on this scale. Only $20 \%$ of the shoppers in our sample indicated no propensity towards deshopping. Whilst not necessarily generalisable more widely, these results suggest that that deshopping may represent a substantial problem for the UK female clothing retailers.

Some qualitative findings are included to add depth to the picture. Some respondents of the questionnaire indicated willingness to take part in further research and voluntarily provided their contact details. Those identified as deshoppers (averaging above the midpoint of the deshopping scale) were contacted with a view to participating in interviews focused on issues regarding their deshopping behaviour. Twelve in-depth semi-structured interviews were carried out.

\section{RESULTS}

Examination of preliminary scatter graphs (Deshopping as the dependent variable, attitude, subjective norm and perceived behavioural control as independent variables) indicated (of course) that $20 \%$ of the points lay on the origin and were thus of no value for modelling. In modelling the behaviour of those respondents who do deshop, these $20 \%$ of respondents could have exerted an undue influence. Those observations were therefore eliminated from our model (following Hair et al., 2007). The remaining observations were distributed more or less evenly in a broadly linear manner on the scatter graphs. Thus, we consider deshopping to be a scale rather than an ordinal variable. Out of 528 participants 266 were identified scoring above the midpoint of the scale. In effect, we interpreted this as meaning that $50 \%$ of the total respondents were more likely than not to deshop.

The multiple regression (SPSS: 'stepwise') model is reported in Table 1 and illustrated in Figure 2. The numbers alongside the independent variables in Figure 2 are the $\beta$ weights (standardised regression coefficients), indicating the 'steepness' of the relationships between the dependent and independent variables on a $0-1$ scale.

Deshoppers (425 respondents)

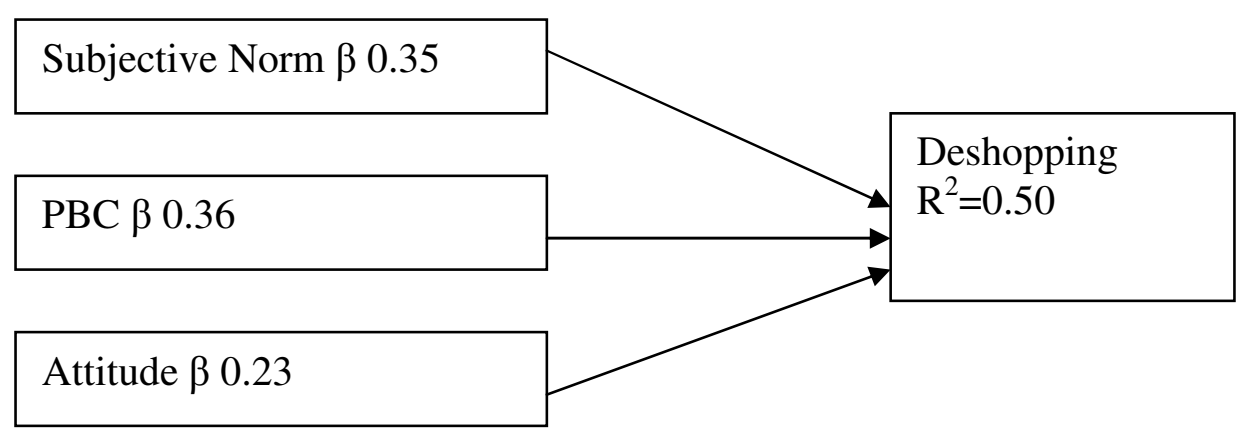

Figure 2: Regression model of deshopping as illustrated 


\begin{tabular}{lcccc}
\hline & $\begin{array}{c}\beta \\
\text { weight }\end{array}$ & $\begin{array}{c}\mathbf{R}^{2} \text { of the model } \\
\text { step }\end{array}$ & $\begin{array}{c}\mathbf{R}^{2} \\
\text { change }\end{array}$ & $\begin{array}{c}\mathbf{F} \\
\text { change }\end{array}$ \\
\hline $\begin{array}{l}\text { Perceived Behavioural } \\
\text { Control }\end{array}$ & 0.36 & 0.32 & 0.32 & 202 \\
Subjective Norm & 0.35 & 0.46 & 0.14 & 113 \\
Attitude & 0.23 & 0.50 & 0.04 & 35 \\
\hline
\end{tabular}

Notes:1. All $\beta$ weights and $F$ change values significant at $p=0.001$, indicating the utility of including each variable in the model.

2. $n=425$. Results are similar for $n=528$.

\section{Table 1. Regression model of deshopping}

The significant $\beta$ weights and $\mathrm{F}$ change indicate that each hypothesis is supported. Attitude towards deshopping (H1), subjective norm $(\mathrm{H} 2)$ and perceived behavioural control (H3) are all significantly associated with deshopping. The initial indications are that procedures can be designed to reduce this behaviour. For example, the correlation of deshopping with perceived behavioural control demonstrates that if deshopping is made difficult, for example by means of monitoring and regulation of the refunds procedure, then the deshopper should be less likely to deshop. The correlation of deshopping with subjective norm demonstrates that the deshoppers are concerned with opinions of people who are important to them. With consumer education, deshopping should become less acceptable and the deshopper should be more likely to discontinue the behaviour.

\section{DISCUSSION AND QUALITATIVE FINDINGS}

The results demonstrate a prevalence of deshopping behaviour and qualitative strength of the TPB variables. Examples from the semi-structured interviews illustrate this behaviour:

"I have done it once because I had worn it and did not like it that much. It was a top from Pilot. I wore it 2-3 times then picked seam, as a reason to go and give it back. I was excited to get my money back and get rid of the top"

(Interviewee 2)

"I had worn trousers for Christmas day and for New Year and enjoyed wearing them and then took them back."

(Interviewee 9).

\section{Attitude to Deshopping Behaviour}

The quantitative results indicated that Attitude is closely associated $\left(\begin{array}{ll}\beta & 0.23\end{array}\right)$ with deshopping. Attitude is qualitatively demonstrated from the interviews:

"Give it a go. The worst that can happen is they will not take it back. They cannot arrest you!"

(Interviewee 1)

"For a special occasion coming up I need a pashmina, just to literally wear to walk in and walk out, with a strapless dress. For a hundred pounds I could get 
one to return it. I would cut off the tag and receipt and keep it in the bag, for return."

(Interviewee 1)

\section{Subjective Norm}

The quantitative association of deshopping with subjective norm $\left(\begin{array}{ll}\beta & 0.35\end{array}\right)$ demonstrates that deshoppers are indeed concerned with opinions of people who are important to them. This is supported by the interviews. For example, Heather got the idea from her best friend and went shopping with her when she did it (Interviewee 3). Lilly feels that she is influenced by friends:

"If they can do it, why can't I?"

(Interviewee 6)

"I have heard of my daughter's friends [she is 28] doing this, and they never have any problems, so I thought if they can all do it then why can't I?"

(Interviewee 9)

The interviews highlight that the respondents are influenced by people (e.g., friends or parents) in a negative way as well as in a constructive and beneficial way. This would suggest that if (non-deshopping) consumers' were educated about the affects of this behaviour in terms of higher prices for everyone, they could influence the deshoppers to reduce the behaviour $-\mathrm{a}$ form of viral marketing.

\section{Perceived Behavioural Control}

This variable was the first and most significant in the stepwise regression model ( $\beta$ $0.36, F=202$ ), indicating that the strongest predictor of deshopping is shoppers perceiving deshopping to be easy. The interviews demonstrate the large element of control that the deshopper perceives they have over the deshopping process and its successful outcome. The interviews highlight the perceived 'ease' with which they carry out deshopping. The strength of this variable indicates that if deshopping is made difficult, for example by means of monitoring and regulation of a refunds procedure then the deshopper should be less likely to deshop. If this perception of control could be altered, e.g. by tightened return policies, the behaviour could be reduced. This is supported by the qualitative interviews. For example, Liz feels that over the last 5-10 years returning has got a lot easier (Interviewee 1). Gail believes that the consequence is not getting a return or exchange, as the police would not be involved as it is not shoplifting or stealing:

"Its just misrepresentation of facts."

(Interviewee 7)

"You can take nearly take anything back, and its not as scary as you think it should be really."

(Interviewee 5)

"I have had managers called over before, but I could argue all day till I get my money back."

(Interviewee 8) 
This is further highlighted by the measures that deshoppers deliberately introduce to reduce the chances of being caught. If deshopping were more difficult or if they would get into 'serious' trouble they would be unlikely to partake in the behaviour, supporting the above indication of the TPB model. For example, Liz plans her response in advance of returning to Gap the garment that she has worn:

\section{"It was purchased for a cousin or niece and they do not want it.'}

(Interviewee 1)

Liz alternates returns between stores so that staff do not recognise her (Interviewee 1). Linda shops where she knows the return policy. She ensures that she only keeps her tops for a little time when she wants to take them back so that there is no problem (Interviewee 4). Hetty will also disassociate herself from blame by saying:

"My sister doesn't like it or it doesn't fit"

(Interviewee 5)

Liz has never been caught deshopping and if she perceived that there was a chance of being caught she would:

"Not have the balls to do it"

(Interviewee 1)

"I was confident it would work as I had done it before."

(Interviewee 3)

"From my experience a lot of the time they don't ask questions"

(Interviewee 5)

"I do this all the time, and never have any problem. It is so easy."

(Interviewee 8)

The research highlights that deshoppers have not encountered serious problems or punishment as a result of fraudulent returns. Deshoppers consider that the worst experience could be being refused a return and therefore having to keep the garment. This past experience is influential in their perception of deshopping as being easy, and contributes to the attitude that they may as well try it because they have nothing to lose. The deshoppers' successful previous experiences enable consumers to have a deeper understanding of the returns process, thus enhancing their knowledge and confidence for the next time.

The results also demonstrate that there is almost no actual control over the behaviour as none of the deshoppers interviewed had ever been caught. The deshoppers perceive that the worst that could happen as a result of the behaviour is not getting a refund. It can be deduced that deshoppers would be less likely to deshop if they perceived it to be difficult. The qualitative findings indicate that just by (very rarely) refusing a refund, retailers are not doing enough to make deshopping difficult. This is because at present, when the deshoppers encounter a refusal of return, it is not recollected as a bad experience. This is therefore not deterring them from partaking in the behaviour again. The interviews particularly demonstrate that if this experience had led to severe 
embarrassment or involved the police or criminal proceedings, it would change the deshoppers actual control and their attitudes.

In summary, all three hypotheses, $\mathrm{H} 1, \mathrm{H} 2$ and $\mathrm{H} 3$, have been supported quantitatively and qualitatively, demonstrating that deshopping is associated with attitude, subjective norm and perceived behavioural control.

\section{CONCLUSIONS AND IMPLICATIONS}

The results suggest that retailers can address perceived behavioural control readily by imposing strict returns procedures. Retailers will need to educate their staff to ask pertinent and polite questions of customers and establish the legitimacy of customer claims for product returns. There are subjective norms and attitudes uncovered by the research so retailers could incorporate these in an education programme to re-educate customers about why the returns policy is there and how it should be used. Retailers need to make a positive effort to shake off the myopic mode and to find ways to engage in dialogue with external agencies such as the media and consumer groups in order to listen to customer concerns and find ways of mutual understanding about problematic areas. Deshopping is an issue of public concern since the buying of goods as new and bringing them back as not new is tantamount to deception. That is, the value would have changed as the difference is the gap between the new value and the second hand value. Wearing clothes and returning them along with any hidden damage will decrease their value. Moreover, when retailers put such clothes back on the shelves for reselling there are increased hygiene risks. Retailers need to move beyond their myopic tendency in regarding deshopping as their internal retailing problem and to recognise that it has broader ramifications for society. Therefore, we recommend that retailers should acknowledge the role that effective marketing communications can play in generating public awareness, e.g. by incorporating aspects concerning good customer behaviour in their use of role models in their advertisements.

When deshopping is identified as harmful to a retailer, it is ineffective for a retailer to continue to try to gain a competitive edge in its marketing strategy by offering a returns policy to increase its customer amenities. Some shops, especially the smaller ones in the UK and some states e.g. Sabah within the Malaysian federation do not encourage customers to return goods for monetary refunds. However, it should be recognised that good quality trade, as Adam Smith observed in his book, The Wealth of Nations, benefits the parties concerned. For a returns policy to be managed constructively there are perceived benefits for both retailers and customers as it reduces the risks and negativities associated with transactions between both parties, thereby increasing mutual trust in the customer retention and loyalty stakes.

Transactional data exists when most organisations keep track of what their customers buy, when, how and through what channels. In our increasingly computerised world such transactional data about their own customers are easily accessible to the retailers concerned. It is advocated that retailers need to collaborate with each other, e.g. within the Retail Consortium and with external credit agencies on the issue of controlling and reducing the problems engendered by deshopping with a greater capacity to set up a central database to screen transactional data for repeat offenders and to prosecute serious offences. 
Hand in hand with a customer education policy would be information for customers as to the detrimental effects of deshopping for retailers and the wider impact on customers in general. The problem is unlikely to go away by itself, so retailers need to have coping strategies with a customer focus to demonstrate to customers that fraudulent returns are offences with serious consequences. Parallels can be drawn from current campaigns encouraging customers not to purchase counterfeit DVDs, highlighting the damaging affect of these product purchases to the industry and thereby the economy, which is ultimately to the detriment of everyone. Retailers could emphasise that there will be a crackdown to stamp out fraudulent returns and that dishonest customers could be prosecuted in the courts. Educating the genuine customer to the problem will aid their participation in the schemes that retailers choose to undertake for returns. Education will also change the perception of deshopping so that it is recognised as poor behaviour with consequences equivalent to shoplifting. Schemes should highlight that deshoppers are not just stretching the goodwill and returns policies of the retailer, but are committing theft. The losers are all shoppers who presumably have to pay a premium on prices to support the deshoppers.

As we suggested in the introduction to this paper, the results confirm that retailers are currently generally myopic in their approaches to the problem of managing returns in face of this problematic, growing behaviour. It is evident that deshoppers find this behaviour easy and retailers appear powerless to do anything to prevent it. The corollary of retailer myopia is that retailers appear to be powerless and thereby condone a practice that is not good for society. Fraudulent returns or deshopping is prevalent and damaging to retailers and hurts their profits, which give them less room to manoeuvre to re-invest in customer-orientated programmes. In the long term, their poor management of returns and methods of detection of deshopping could damage the all important and fragile retailer-customer relationship.

The current retail environment is very competitive leading to pressure on margins. Protection from unnecessary shrinkage is vital. Modern retailers cannot afford to be myopic about deshopping. We consider that considerable competitive advantage for retailers, associated with potentially lower prices for shoppers, can be achieved as a result of these findings.

\section{ACKNOWLEDGMENTS}

The authors thank Professor Robert East for providing the 'NEWACT' program and the anonymous reviewers of Brunel University's Working Paper series for their helpful suggestions.

\section{REFERENCES}

Ajzen, I. (1985), "From Intention to action: a theory of planned behaviour", in Kuhl, J. and Beckman, J. (eds.), Action Control: From Cognitions to Behaviours, New York: Springer.

Ajzen, I. (1991), "The Theory of Planned Behaviour", Organisational Behaviours and Human Decision Processes, Vol. 50, pp.179-211.

Ang, L. and Buttle, F. (2006) "Managing For A Successful Customer Acquisition: An Exploration.” Journal of Marketing Management Vol. 22, pp. 295-317. 
Bamfield, J. and Hollinger, R. (2001), Managing losses in the retail crime store: A comparison of loss prevention activity in the United States and Great Britain. In Occupational Crime (Ed.) Mars, G. (ed), Aldershot, Ashgate Press.

Bennett, R (1997), "Anger, Catharsis and Purchasing Behaviour Following Aggressive Customer Complaints", Journal of Consumer Marketing, Vol. 14, No. 2 pp.156-171.

Bloch, P.H., Sherrell, D.L. and Ridgway, N.M. (1986), "Consumer search: An extended framework", Journal of Consumer Research, Vol. 13, June, pp.119126.

Boldero, J., Moore, S. and Rosenthal, D. (1992), "Intentions Context and Safe Sex", Journal of Applied Social Psychology, Vol. 22, No. 17, pp. 1374-96.

Breakwell, G.M., Hammond, S. and Fife-Schaw, C. (2000), Research Methods in Psychology, $2^{\text {nd }}$ edition, London, Sage.

Bush, A.J. and Hair, J.F. (1985), "An assessment of the mall intercept as a data collection method", Journal of Marketing Research, Vol 22, No. 2, pp. 158167.

Buttle, F. (2004), Customer Relationship Management: Concepts and Tools, Oxford, Elsevier/Butterworth Heineman.

Cole, C.A. (1989), "Deterrence and Customer Fraud", Journal of Retailing, Vol. 65, No. 1, pp. 107-120.

Darden, W. and Rao, C. (1979), "A Linear Covariant Model of Warranty Attitudes and Behaviours", Journal of Marketing Research, Vol. 16, No. 4 pp. 466-77

Davis, D. and Consenza, R.M. (1988), "Business Research for Decision Making", $2^{\text {nd }}$ edition, Boston, PWS-Kent.

Devries, H. and Backbier, E. (1994), "Self Efficiency as an Important Determinant of Quitting Among Pregnant Women Who Smoke: The PHI Pattern", Preventative Medicine, Vol. 23, No. 2, pp. 167-74.

Donovan, R., Rossiter, J., Marcoolyn, G. and Nesdale, A. (1994), "Store atmosphere and purchasing behaviour", Journal of Retailing, Vol. 70, pp. 283-294.

East, R. (1997), Consumer Behaviour, Hemel Hempstead UK, Prentice Hall (including accompanying 'NEWACT' and 'README PC Files).

Elliot, R. (1997), "Symbolic Meaning and Post-Modern Culture". In: Bromlie, D. et al (Eds) Rethinking Marketing, London, Sage.

Gardner, D. M., Harris, J. and Kim J (1999), "The Fraudulent Consumer”, paper at 1999 Marketing and Public Policy Conference, University of Notre Dame, May 20-22.

Goodwin, R. and Ball, B. (2003), "What Marketing Wants the CEO to Know", Marketing Management, Vol. 12, No. 5, pp. 18-23.

Greenberg, B., Bellenger, D., Robertson, D. and Parameswaran, R. (1979), “An Analysis Of Return Prone Consumers", Proceedings of 1979 Southern Marketing Association Meetings, pp. 252-258.

Guthrie, J (1997), 1996 New Zealand Survey of Retail Theft and Security, Dunedin, New Zealand: University of Otago.

Hair, J.F., Black, W., Babin, B., Anderson, R. and Tatham, R.L. (2007), Multivariate Data Analysis, $6^{\text {th }}$ edition, New Jersey, Prentice Hall.

Hanna, N. and Wozniak, R. (2001), Consumer Behaviour: An Applied Approach, Prentice Hall, Upper Saddle River, NJ.

Hoch, S.J. and Loewenstein, G.F. (1991), "Time-inconsistent preferences and consumer self control", Journal of Consumer Research, Vol. 17, March, pp. 92-507. 
Hogarth, J., English, M., and Sharma, M. (2001) "Customer Complaints and Third Parties: Determinants of Customer Satisfaction with Complaint Resolution Efforts", Journal of Consumer Satisfaction, Dissatisfaction and Complaining Behaviour. Vol. 14, pp. 74-86

Hollinger, R., Dabney, L. and Hayes, R. (1996) 1996 National Retail Security Survey: Final Report, Florida, University of Florida.

Jolson, M. (1974) "Consumers as Offenders", Journal of Business Research, Jan. pp. 89-98.

Kardes, F. and Kim, J. (1991), "Consumer Inference", co-chairs of a special topic session presented at the" Annual Conference of the Association for Consumer Research, Chicago, IL.

Knedall, C and Russ, F. (1975), "Warranty And Complaints Policies: An Opportunity for Marketing Management", Journal of Marketing, Vol. 39, No 2, pp. 36-43.

Jarboe, G.R. and McDaniel, C.D. (1987), "A profile of browsers in regional shopping mall”, Journal of Academy of Marketing Science, Vol. 15, Spring, pp. 45-52.

Johnson, S. L., Sommer, R., and Martino, V. (1985) "Consumer Behavior at Bulk Food Bins", Journal of Consumer Research, Vol. 12, No. 1, pp. 114-117.

Jolson, M. (1974), "Consumers as Offenders" Journal of Business Research, Vol. 2 (January), pp. 89-98.

King, T. and Dennis, C.E. (2003), "Deshopping behaviour: a theory of planned behaviour analysis", International Journal of Retail and Distribution Management, Vol. 31, No. 3, pp.153-163.

King, T. and Dennis, C.E. (2006), "Unethical consumers: deshopping behaviour using the analysis of theory of planned behaviour", Qualitative Market Research, Vol 9, No 1, pp. 282-296.

King, T., Dennis, C.E. and McHendry J (2007) "The management of deshopping and its effects on service: A mass market case study", International Journal of Retail and Distribution Management, Vol. 35, No. 9, pp. 720-733.

Levitt, T. (1960), "Marketing Myopia”, Harvard Business Review, Vol 38, (July/August), pp. 45-56.

McClure, P. and Ryans, J. (1968), "Differences Between Retailers and Consumer Perceptions", Journal Of Marketing Research, Vol. 5, No. 1, pp. 35-40.

Mitchell, V. and McGoldrick, P. (1996), “Consumers' Risk Reduction Strategies : A Review And Synthesis", The International Review Of Retail, Distribution, And Consumer Research, Vol. 6, No. 1, pp. 1-33

Naylor, G. and Kleiser, S. (2000), "Negative Versus Positive Word-Of-Mouth: An Exception To The Rule", Journal Of Consumer Satisfaction, Dissatisfaction And Complaining Behaviour, Vol. 13, pp. 26-38.

Nowell, C. and Stanley, L.R. (1991), "Length-biased sampling in mall intercept surveys", Journal of Marketing Research, Vol 28, No 4, pp. 475-480.

Olsen, J. (1972), "Cue Utilisation In The Quality Perception Process". In M.Venkatesan (Ed) Proceedings Of The Third Annual Conference Of The Association For Consumer Research, Chicago: Association For Consumer Research, pp. 167-79.

Perry, M. and Perry, A. (1976), "Service Contract Compared To Warranty as a Means to Reduce Consumers Risk", Journal of Retailing, Vol. 52, No 2, pp. 33-40.

Richins, M. (1983), "Negative Word of Mouth by Dissatisfied Customers: A Pilot Study," Journal of Marketing, Vol. 47, pp. 68-78.

Roselius, E. (1971) "Consumer Rankings of Risk Reduction Methods", Journal of Marketing, Vol. 35, No. 1 (Jan.), pp. 56-61. 
Sargeant, A. and West, C. (2001), Direct and Interactive Marketing, Oxford, Oxford University Press.

Schmidt, R., Sturrock, F., Ward, P. and Lea-Greenwood, G. (1999), "Deshopping The Art of Illicit Consumption", The International Journal of Retail and Distribution Management, Vol 27, No 8, pp. 209-301.

Stokes, D. and Lomax, W. (2002), "Taking Control of Word of Mouth Marketing: The Case of the Entrepreneurial Hotelier", Journal of Small Business and Enterprise Development Vol. 9, No 4, pp. 349-357.

Stone M, Cox D and Wiltshire G. (2002), "Complaints management in financial services", International Journal of Customer Relationship Management, Vol 5, No1, pp. 43-52.

Stone M. (1999), "Managing good \& bad customers", Part 2, Journal of Database Marketing Vol 6, No 4, pp. 299-314.

Roselius, E. (1971) "Consumer Rankings of Risk Reduction Methods", Journal of Marketing, Vol 35, No 1, pp. 56-61.

Tabachnick, B. G. and Fidell, L. S. (2001) Using Multivariate Statistics, $4^{\text {th }}$ edition, Boston Mass, Allyn and Bacon.

The Theft Act (1968), Available from: The Law Teacher The Theft Act, http://www.lawteacher.net/Criminal/Property\%20Offences/TA\%201968.pdf, [accessed 28 August 2007].

Titus, P.A. and Everett, P.B. (1995), "The consumer retail search process: a conceptual model and research agenda", Journal of the Academy of Marketing Science, Vol. 23, No. 2, pp. 106-119.

Underhill, P. (1999), Why we buy: The science of shopping, New York, Simon and Schuster.

Warde, A. (1994), "Consumption, Identity-formation, and Uncertainty", Sociology, Vol. 28, No. 4, pp. 877-898.

Ward, P. and Sturrock. F. (1998), "She Knows What She Wants .... Towards a Female Consumption Risk Reduction Strategy Framework", Marketing Intelligence And Planning, Vol. 16, No. 5, pp. 327-336.

Ward, P., Sturrock F. and Schmidt, R. A. (1998), "To Shop or Deshop - That is the Question", Proceedings of the Academy of Marketing Conference, Sheffield.

Wilkes, R. (1978), "Fraudulent Behaviour by Consumers," Journal of Marketing, Vol. 42 (October), pp. 67-76.

Wright, L.T., Newman, A. and Dennis, C. "Enhancing consumer empowerment", European Journal of Marketing, Vol. 40, No. 9-10, pp. 925-935.

Zabriskie, N. (1972-1973), "Fraud by Customers", Journal of Retailing, Vol. 48, (Winter), pp. 22-27.

\section{ABOUT THE AUTHORS}

Tamira King has a doctorate and is a Marketing Lecturer and MSc Marketing course director at Brunel University. Her research interest is in a consumer behaviour named 'deshopping', the ethics of fraudulent consumption and the evolutionary psychology of male and female shopping behaviours. Tamira works closely with retailers and her work aims to improve the management of customer service and the returns process. Tamira's teaching is in the areas of retail management and marketing.

Charles Dennis is a Senior Lecturer in Marketing and Retail Management at Brunel University, London, UK. He has published widely on consumer behaviour and "why people shop where they do". The text book Marketing the E-business (Harris and 
Dennis 2002; $2^{\text {nd }}$ edition 2007) and research based E-Retailing (Dennis et al., 2004) are published by Routledge; and the research monograph Objects of Desire:

Consumer Behaviour in Shopping Centre Choice, (Dennis, 2005) by Palgrave.

Len Tiu Wright has a doctorate, is Professor of Marketing and Research Professor at De Montfort University, Leicester and Visiting Professor at the University of Keele. She has held full time appointments at the universities of Keele, Birmingham and Loughborough and visiting lecturing positions with institutions in the UK e.g. Cambridge University and overseas. Len Tiu has retailing, consultancy and industrial experience and has researched in the Far East, Europe and North America. Her writings have appeared in books, in American and European academic journals, and at conferences where some have gained best paper awards. She is on the editorial boards of a number of leading marketing journals. She is the Founding Editor of the Qualitative Market Research - An International Journal, an Emerald publication. 